\title{
Anaesthetic management in the excision of large carotid body tumours: Surgeons perspectives
}

\author{
Salins S.R ${ }^{1}$, Prabhu P.K ${ }^{2}$, Stephen $E^{3}$, Selvaraj $D^{4}$ \\ ${ }^{1}$ Dr. Serina Ruth Salins, Department of Anaesthesia, ${ }^{2}$ Dr. Prabhu Prem Kumar, Department of Vascular Surgery, \\ ${ }^{3}$ Dr. Edwin Stephen, Department of Vascular Surgery, ${ }^{4}$ Dr. Deepak Selvaraj, Department of Vascular Surgery; all authors \\ are attached with Christian Medical College, Vellore, Tamil Nadu, India.
}

Address for Correspondence: Dr. Serina Ruth Salins, Email: serinaruthsalins@gmail.com

\begin{abstract}
Objective(s): Carotid body tumours (CBT) are considered rare. Surgical excision is the treatment of choice and poses many anaesthetic challenges especially in large tumours. In this paper we present our experience of anaesthetic management of CBT which is one of the largest series on management of large (Shamblin II, III) tumours in the world. Design: Retrospective cohort, Instituitional Review Board (IRB) Approved. Setting: Single-Centre Tertiary care institute in South India. Participants: Patients undergoing operative intervention for carotid body tumours. Interventions: nil, observational. Results: 66 tumours were excised in 62 patients ( 27 female, 39 male). The average age was 37.5 . All tumours presented with a slow growing neck mass. 7 patients complained of pain,as the presenting symptom. 2 were malignant, all were non-functional. 4 presented with preoperative neurological dysfunction- 2 with cranial nerve palsy following excision of contralateral CBT and 2 with resolved stroke following preoperative embolization. Nasotracheal intubation with mandibular subluxation was performed in 5. The average operating time was 2.5 hours. Average blood loss was $900 \mathrm{ml}$ (200-5000ml). Perioperative blood or product requirement varied from no transfusion to one patient with a very large $(20 \mathrm{~cm}$ tumour) requiring transfusion of a total of 20 products. Clamping of the carotid was necessary in 22 patients. 3 patients received heparin prior to clamp. There were 4 perioperative strokes, none of whom had any precipitous intraoperative hypotension. Transient postoperative cranial nerve palsy/paresis occurred in 50\% with permanent cranial nerve deficits in 5\%. There was no perioperative mortality. Tracheostomy was required in one patient for bilateral vocal cord palsy. Conclusions: Several preoperative, intraoperative and postoperative management points (airway, intraoperative blood loss, stroke, cranial nerve dysfunction, blood pressure control), are specific to the management of carotid body $\mathrm{F}$ tumours. Increased awareness of these specific scenarios and appropriate management ensures minimal perioperative morbidity and mortality.
\end{abstract}

Keywords: CBT, preoperative embolization, Nasotracheal intubation, blood pressure control.

\section{Introduction}

Carotid body tumours (CBT) are considered rare. However, they are the most common head and neck paragangliomas.Our experience of management of CBT is one of the largest series on management of large (Shamblin II, III) tumours in the world [1]. This article presents a brief description of our case series of carotid body tumours with regard to presentation, management and outcomes. We detail the anaesthetic management involved in resection. We then review some of the rare

Manuscript received $10^{\text {th }}$ July 2016

Reviewed: $24^{\text {th }}$ July 2016

Author Corrected: $4^{\text {th }}$ August 2016

Accepted for Publication $14^{\text {th }}$ August 2016 atypical complications encountered in large bilateral tumours and review their management. Increased awareness of these specific scenarios and appropriate management ensures minimal perioperative morbidity and mortality, as shown in a study conducted at Christian medical college, Vellore, India. The study included 32 patients, with a total of 48 tumours, thirty four of which were excised. Shamblin II/III tumours were associated with transient nerve palsy in $32.3 \%$ cases. $5.8 \%$ of their cases had peri-operative stroke and were in the Shamblin-III group. Three patients had persistent nerve palsy, accounting for $8.8 \%$ of the cases. 
The authors concluded that higher Shamblin grade tumours had more neurological complications and that pre-operative embolization did not reduce neurological complications [1].

\section{Materials and Methods}

We performed a retrospective review of the inpatient, anaesthetic and outpatient records from $1^{\text {st }}$ January, 2005 to $31^{\text {st }}$ December 2014. All patients with carotid body tumours were enrolled in the study.

Pre-operative management: Surgical excision is the treatment of choice and poses many anaesthetic challenges (airway, intraoperative blood loss, stroke, cranial nerve dysfunction, blood pressure control) especially in patients presenting with large or bilateral tumours. The clinical features, systemic review, airway, in way of Mallampati grade, neck movements, and indirect laryngoscopy for vocal cord movement and position, were assessed and documented.

Details of comorbid medical illness, pre-existent stroke, cranial nerve complications, imaging, preoperative embolization, tumour size and expected surgical difficulty (Shamblin grade) were also documented. Additionally, the anaesthetic management protocol were confirmed and the preoperative plan for intubation was made in discussion with the operating surgeon and details of this were assessed.

Haemoglobin, blood sugar, electrocardiogram, bleeding parameters (platelets, prothrombin time with INR, activated partial thromboplastin time), renal function tests, chest radiograph and echocardiography, where indicated, were done. Doppler study showed hypervascular lesion at the right carotid bifurcation suggestive of CBT. Informed consent was taken from the patient.

Intraprocedural management: All patients were kept fasting for at least 6 hours for solids and 2 hours for liquids preoperatively. Patients with small tumours were premedicated with oral lorazepam $1 \mathrm{mg}$ and omeprazole $40 \mathrm{mg}$, one hour before surgery. Patients with preexistent cranial nerve deficits (CN IX, X, XII) who had impaired gag or cough reflex were not prescribed sedative premedication. Anaesthetic machine \& equipment including suction were checked, monitors calibrated and emergency drugs, such as, atropine, ephedrine, phenylephrine, noradrenaline, adrenaline, were pre-loaded from the start of surgery, and vasopressin, calcium potassium,

sodabicarbonate, were kept easily available. Monitors used were ECG, $\mathrm{SpO} 2, \mathrm{EtCo} 2,(\mathrm{Et})$ isoflurane, with minimum alveolar concentration, heart rate, arterial blood pressure with pulse pressure variation, temperature, urine output and ventilation variables.

A wide bore peripheral, central and arterial line was placed in all patients for continuous monitoring. Prophylactic antibiotics were administered. Nondextrose containing maintenance fluids, such as Hartmann's solution, about $2 \mathrm{ml} / \mathrm{kg} /$ hour, with colloids, blood and blood products, as required, were used, to maintain an urine output of at least $1 \mathrm{ml} / \mathrm{kg} /$ hour.

Majority of the patients, after preoxygenation, were induced with fentanyl, propofol/ thiopental, suxamethonium, vecuronium or atracurium, intubated, maintained with $\mathrm{O} 2$, air, isoflurane, morphine, paracetamol and at emergence- $\mathrm{O} 2$, ondansetron, glycopyrrolate and neostigmine (as reversal agents), there after shifted to recovery room or HDU/ICU, depending on the response of the patient, intraoperative course and preoperative plan. Awake fiberoptic intubation or video-assissted laryngoscopy, was utilized for patients with large tumours causing compression of the nasopharynx.

Blood was cross-matched and was available in the OR at the start of surgery. Patient was positioned in a head up position with a roll under the shoulder to reduce venous pooling. This decreases the additional risk of air embolism and helps in reduction of blood loss. Intraoperative use of tranexamic acid $(10-15 \mathrm{mg} / \mathrm{kg})$ in patients with high volume blood loss and dexamethasone in those requiring nerve handling was dependent on the managing team. A small bore (14G) nasogastric tube was inserted in large tumours.

This served as a guide to the pharynx intraoperatively and was used for feeding post-op till the transient swallowing difficulty resolved. At closure, local anaesthetic infiltration, with $0.25 \%$ Bupivacaine or $0.2 \%$ Ropivacaine, of the wound was performed for post operative pain relief. Extubation was planned in all patients except in those with suspected tracheomalacia where a trial of extubation or tracheostomy was done. An assessment of the vocal cords was done at extubation. 


\section{Results}

All tumours presented with a slow growing neck mass. Seven patients also complained of associated pain. Two tumours were malignant, all were non-functional. All patients had undergone preoperative imaging with CT angiogram. All patients underwent operation under general anaesthesia. There was no perioperative mortality. Tracheostomy was required in one patient for bilateral vocal cord palsy. Other clinical details are presented in Table-1 below.

\begin{tabular}{|c|c|}
\hline Results & Numbers \\
\hline Number of patients & 62 \\
\hline Number of tumours & 66 \\
\hline Gender & 26 female, 36 male \\
\hline Average age & 37.5 \\
\hline Duration of tumour at presentation & 3.4 years (2 months- 13 years) \\
\hline ASA grade & $\begin{array}{c}\text { Grade I } 48 \\
\text { Grade II } 18\end{array}$ \\
\hline Preoperative complications & 4 \\
\hline Embolization & 25 \\
\hline Airway Mallampati score & $\begin{array}{l}\text { Grade } 1-36 \\
\text { Grade } 2-24 \\
\text { Grade } 3-6 \\
\text { Grade } 4-0\end{array}$ \\
\hline Laryngoscopy score & $\begin{array}{c}\text { Grade } 1-23 \\
\text { Grade } 2-35 \\
\text { Grade } 3-8 \\
\text { Grade } 4-0\end{array}$ \\
\hline Intubation nasal/ oral / fiberoptic & $\begin{array}{c}\text { Nasal- } 5 \\
\text { Oral - } 60 \\
\text { Video-assisted- } 1\end{array}$ \\
\hline Neck movement & $\begin{array}{l}\text { Normal -65 } \\
\text { Restricted-1 }\end{array}$ \\
\hline Anaesthetic agents & $\begin{array}{l}\text { Induction \& Maintenance - oxygen, fentanyl } \\
\text { thiopentone, propofol, vecuronium, morphine, } \\
\text { isoflurane } \\
\text { Emergence- Ondansetron, glycopyrrolate, neostigmine }\end{array}$ \\
\hline Carotid clamping & 22 \\
\hline Haemodynamic changes & 18 \\
\hline Blood loss & $900 \mathrm{ml}(200-5000 \mathrm{ml})$ \\
\hline Monitoring PPV & 58 \\
\hline ICU/HDU & 22 \\
\hline Intraoperative complications & Nil \\
\hline Postoperative complications & $\begin{array}{c}\text { Stroke-4 } \\
\text { Transient cranial nerve palsy- } 33 \\
\text { Tracheostomy-1 }\end{array}$ \\
\hline Mortality & Nil \\
\hline
\end{tabular}




\section{Discussion}

CBTs are slow-growing, asymptomatic tumours in the carotid triangle.Large tumours can cause compressive symptoms like pain, change in voice, hoarseness, pain or difficulty in swallowing, jaw stiffness, sore throat or cranial nerve deficits $(1,2)$. Palpitations, tachycardia, and hypertension can be present in functional tumours [1,2]. The doubling time for the tumours is about 5 years, however, excision is the gold standard of treatment due to the risk of morbidity from compression symptoms and the possibility of malignant transformation $[3,4]$. Though previously thought to occur in those staying at higher altitudes, it can be present in other populations as well [5-7]. CBT can be sporadic or familial, the latter have a higher chance of multiple, multifocal, functional, recurrent or malignant tumours.

Malignancy in these tumours is diagnosed if there is a metastasis to distant organs (lung, liver) but does not preclude excision of the primary [1-5]. Other rare presentations like syncope, transient ischaemic attack, cardiac arrest, obstructive sleep apnoea and neck pain have also been reported. They can also occur as a part of multiple endocrine neoplasia. Clinical diagnosis is backed up with computed tomography and angiography to diagnose these tumours [1]. Fine needle aspiration and biopsy are ill advised due to the risk of bleeding. Some patients with inoperable, residual or recurrent tumours receive postoperative radiotherapy [5].

Carotid body tumours (CBT s) were first described by Lushka. First attempts at resection were by Riegner, Maydl and Scuddder. These initial procedures were associated with a high rate of neurological morbidity which subsequently reduced with improvements in operative technique and anaesthesia [1-4]. The operative management is planned depending on the Shamblin grade of the tumours and the proximity to the skull base. Group-I tumours are localized and easily resected. Group-II are adherent or partially surrounding vessels and may require carotid clamping intra-procedure. Group-III tumours intimately surrounding or encasing vessels and require carotid cross- clamping with reconstruction of the carotid bifurcation $[7,8]$.

Anaesthesia is planned to allow for mandibular subluxation or mandibular osteotomy if necessary for access to the skull base [1]. The skin incision lies along the anterior border of the sternocleidomastoid extending behind the ear till the mastoid. It is curved away from the angle of mandible to avoid injury to the marginal mandibular nerve. After vascular control, sub/periadventitial dissection is done in an antegrade and retrograde method to resect the CBT off the carotid bifurcation [7]. The ansa hypoglossi is usually sacrificed if they are in way of safely excising the tumor, with no clinical consequneces. The hypoglossal, spinal accessory, vagus and laryngeal nerves are preserved.

There are many anaesthetic concerns in the management of these tumours which are described in the following sections.

Airway planning: General anaesthesia and continuous cervical plexus block are used in the anaesthetic management of CBT, the latter reserved for patients who are not fit for general anaesthesia [9]. Though cervical block has its advantages, it is not universally acceptable especially in patients with very large tumours where a good exposure of the neck reaching the skull base is necessary. Good surgical exposure is critical and nasotracheal intubation facilitates this thus helping in reduction of post-operative neurological complications and unnecessary ICA sacrifice in large tumours [9-12]. In our series we did not use cervical plexus block as no patient was found suitable.

Five patients underwent nasotracheal intubation due to the presence of very large tumours reaching the skull base in our series. Nasotracheal intubation is conventionally used for surgery in the oral cavity. This allows the mandible to close and thus in neck surgery provides the operating team an additional 2 to 3 centimeter of space towards the skull base [912]. A deeper plane of induction is necessary as the nasal airway is more stimulating. Following preparation with vasoconstrictors xylometazoline (otrivine), ephedrine or adrenaline) nasal drops, a throat pack is placed to allow secretions to collect in the pack and prevent aspiration. A tail is left sticking out of the oral cavity to facilitate removal at the end of surgery. The nasotracheal tube is one size lesser than an orotracheal tube and is fixed at $26 \mathrm{~cm}$ from the nares. The nostril opposite to the operative field is preferred to avoid pressure on the tube and provide the surgeon a better field. A Magill's forceps is used to redirect tube. Complications like nasal bleed, tube entering a false passage, esophageal intubation or kinking of the tube are avoidable with use of a supported tube, careful placement and monitoring. Extubation should be smooth after thorough suctioning and removal of the throat pack. 
Preoperative embolization was performed in 25 patients to reduce the intraoperative blood loss as well make the tumours more firm to assist in the dissection. Also cross circulation was evaluated. Embolization and covered stents are useful in large tumours to reduce blood loss and these are usually performed on the morning of the surgery or a day before [13,14]. In a patient with airway compromise due to a large tumours, intubation may be necessary before embolization to secure the airway and prevent respiratory compromise due to post embolization edema.

Blood loss and hemodynamics management: Blood loss is expected and measures to ensure adequate volume status are initiated. Transfusion triggers parallel, what is followed for other conditions. The allowable blood loss is calculated based in the patient's initial and final lowest acceptable hemoglobin/hematocrit, weight and age according to Table-2 below.

\begin{tabular}{|c|c|c|c|}
\hline \multicolumn{2}{|c|}{$\begin{array}{c}\text { Allowable blood loss } \\
(\mathrm{ABL})=\end{array}$} & Estimated blood volume (EBV) $\mathrm{|}$ \\
\cline { 2 - 3 } & \multicolumn{2}{|c|}{ Hi } \\
\hline Where & $\mathrm{Hi}=$ & Initial Haematocrit & \multicolumn{1}{|c|}{} \\
\hline & $\mathrm{Hf}=$ & Final Haematocrit & \\
\hline
\end{tabular}

\section{Estimated blood volume $(\mathrm{EBV})=$ Weight $(\mathrm{Kg}) \times$ Average Blood Volume}

\begin{tabular}{|c|c|}
\hline Average blood volume & Blood Volume $(\mathrm{ml} / \mathrm{kg})$ \\
\hline Age & 95 \\
\hline Premature neonates & 85 \\
\hline Full term neonates & 80 \\
\hline Infants & 70 \\
\hline Adult men & 65 \\
\hline Adult women & \\
\hline
\end{tabular}

Whole blood or packed cells are transfused. Transfusion may need to be started early only in cases where massive blood loss is expected. This is primarily because once the vascular pedicle to the tumours is ligated or controlled; blood loss can usually be stemmed $[1,13]$.

The role of tranexamic acid administration: bolus and infusion intraoperatively is not very well studied, however, has a definite role in larger tumours. In centres with experience in handling these tumours, blood loss can be limited with no periprocedural transfusion.

However, cross matching at least two units of blood for medium sized and four for larger tumours is prudent to avoid intraoperative transfusion delay.

Hemodynamic fluctuations may arise from factors other than simple volume loss. Bradycardia or hypotension is anticipated during tumour handling especially when the part of the tumour at the bifurcation of the carotid (where it is most adherent) is handled. Dialogue with the operating surgeon to stop tumour handling and infiltrate local anaesthetic is occasionally feasible if there are massive haemodynamic swings. Atropine may be required to normalise the heart rate.

The mainstay of reducing intraoperative cranial nerve injury and carotid cross clamp duration is to prevent excessive intraoperative blood loss. Patients in whom arterial reconstruction is planned are prescribed antiplatelets (Aspirin $75 \mathrm{mg}$ ) 
preoperatively and require systemic intra-procedure heparinisation [15]. This has been shown to reduce the risk of postoperative stroke, however, the decision to proceed with heparinisation depends on the operating surgeon. If clamping is required in a patient with a deficient cross circulation, or prolonged clamp duration is anticipated; intravenous heparin $5000 \mathrm{IU}$ as a bolus can be administered. There is usually no role for subcutaneous heparin or a continuous infusion. Partial reversal with protamine may be required to achieve haemostasis. Tumours in which the vessels have been handled extensively/ reconstructed tend, to be thrombogenic and complete reversal of anticoagulation is necessary only if there is a problem with surgical hemostasis.

Neuroprotection and cranial nerve deficits: Preventing hypoxia and cerebral oedema maintains the intracranial pressure. Cerebral blood flow (CBF) is normally 750ml/minute. The targeted Mean Arterial Pressure (MAP) is 60$160 \mathrm{mmhg}$ to achieve a Cerebral Perfusion Pressure (CPP) of $80-100 \mathrm{mmHg}$. Anaesthetic drugs like thiopentone is neuroprotective, as it causes constriction of cerebral vasculature thereby, decreases cerebral blood flow, cerebral blood volume, ICP, and greater cerebral oxygen consumption [16]. Volatile anaesthetic agents, such as Isoflurane, Desflurane and Sevoflurane are advantageous in terms of decreasing the cerebral metabolic rate with minimal increase of cerebral blood flow and intracranial pressure [17]. Majority of the cases were induced and maintained with oxygen, fentanyl, thiopental (or propofol), vecuronium/atracurium (+/-scoline to assist rapid sequence intubation), isoflurane, morphine, ondansetron and reversal agents (neostigmine \& glycopyrolate), with no additional cerebral protection monitoring. However, PPV(Pulse Pressure Variation) was used to monitor the fluid status, which was very useful.

Various other factors are also involved: maintenance of normocarbia (EtCo2 of 30- 35; Paco2 of 20-80mmhg) with respiratory rate of $10-12 /$ minute, tidal volume of $6 \mathrm{ml} / \mathrm{kg}$ is targeted. Temperature is maintatined at and around 37 degrees celcious with administration of warm saline, forced air warming devices and humidified oxygen. Blood sugars are checked hourly in diabetics, every once in 4 hours. If less than $80 \mathrm{G} / \mathrm{dl}, 50 \mathrm{ml}$ of $50 \%$ dextrose is administered, avoiding continuous infusion of dextrose containing fluids [16,17]. Maintaining cerebral perfusion is essential but the role of cerebral monitoring using transcranial Doppler, jugular venous oximetry, electroencephalogram or near infrared spectrometry is not well established [18,19]. We do not routinely employ these methods. Maintaining a good mean arterial pressure with a relatively low systolic head during periods of blood loss and a high systolic pressure head during carotid clamping ensures optimal cerebral perfusion. With adequate fluid and blood replacement clamping is otherwise well tolerated in these systemically fit patients provided the cross circulation is adequate to maintain the cerebral perfusion. The operative excision can be challenging, requiring partial clamping of the cerebral circulation; and tight control of blood pressure is necessary at all times.

The chemoreceptor cells in the carotid body sense the intravascular pressures of acid $\left(\mathrm{H}^{+}\right)$, oxygen, carbon dioxide and mitochondrial nitric oxide. During hypoxia enhanced carotid body chemoreflex sensitivity reflexively increases the rate and depth of ventilation, increasing blood pressure and heart rate [20].

Apnea (non-obstructive, central) is related to the ablation of the afferent sensory entila causing dysregulation of respiratory automaticity during non-REM sleep (24-26). Hypoventilation, a variable decrease in hypoxic ventilation responsiveness, attenuation of $\mathrm{CO} 2$ sensitivity and increase in breath hold time. Cardiovascular (autonomic) automaticity can also affected; resulting in a baroreflex failure syndrome [21, 22]. Reflex arc dysregulation causes fluctuations in blood pressure with hypertensive attacks or hypotensive episodes can present with symptomatic hypertensive episodes (frontal headache, nausea, vomiting, skin flushing) and sinus tachycardia with intermittent hypotension and bradycardia which can be labile and difficult to treat. Treatment with clonidine, low dose beta-blocker, metoprolol and sedatives has been reported [21, 22]. The anaesthetist should keep a close watch on the rhythm following excision; especially in those with pre-existent cardiac pathology (20-26). These effects usually resolve with time but the exact causation and prognostic factors remain unknown.

Postoperative care- Patients especially those with larger tumours need continuous close monitoring. Patients with large complicated tumours (increased blood loss, haemodynamic fluctuations, preoperative stridor) are monitored in the high dependency unit/ ICU until stable. Complications like bleeding or graft thrombosis may necessitate emergency return to the operating room. Post-operative monitoring is essential as a stroke may not manifest at extubation but occur soon after 
in the postoperative period. Early diagnosis and prompt intervention/ therapy is essential to present permanent disability. In our study, post operative patients were monitored in the high dependency or intensive care unit. This facilitated early and accurate pick up of post-operative complications and early intervention. All patients with post operative strokes had MRI and intensive input from a senior neurologist.

Other complications like cranial nerve palsy and swallowing difficulty are managed symptomatically. Though these are transient, they may be pronounced in the immediate post-operative period due to surgical handling. Precautions in initiation of post operative feeding are imperative. A trial of swallowing fluid is done under supervision. If the patient is able to do so, the nasogastric tube is removed and soft diet is allowed. If the patient complains of regurgitation/ coughs, oral feeding is not initiated. Most patients have such a problem in the first week after surgery but this shows signs of resolution after 2-3 days. Patients are taught swallowing manoeuvres and the NG is used for feeding till they are comfortable with oral feeds. A small bore NG is useful in this scenario as a larger NG is not well tolerated and has a higher risk of problems in patients with impaired airway reflexes. In patients with pre or intraoperative nerve damage placement of a nasogastric tube/ feeding jejunostomy or gastrostomy may be needed if the deficit is severe until the nerve functions recover.

In patients with large long-standing bilateral tumours, laryngomalacia may necessitate elective ventilation, trail of extubation or tracheostomy [27]. The latter may also be necessary in patients with bilateral vocal cord palsy either from iatrogenic injury or compression by tumour. No patient in our cohort had laryngomalacia.

\section{Summary-}

1) Anaesthesia for carotid body tumours needs preoperative discussion with the operating team

2) Nasotracheal intubation is warranted in large tumours where mandibular subluxation is considered

3) Adequate blood and product cover should be available for resections of large tumours

4) Close monitoring of blood pressure is needed during dissection- systolic blood pressures should be kept low.

5) If carotid artery clamping is necessary, the systolic and mean pressure need to be raised to ensure adequate cerebral circulation via the Circle of Willis.

6) Anticoagulation is necessary if the carotid is clamped.

7. Cerebral hypoperfusion maybe a cause for delayed awakening, there should be a high index of suspicion for postoperative stroke as this complication requires immediate intervention

8) Nasogastric tube should be removed only after assessment of swallowing reflexes (in the ward) and not at extubation.

\section{Conclusion}

The anaesthetist has a significant role in the management of CBT. They have to be involved in the preoperative planning and have multiple contingency plans to ensure secure airway, cerebral protection, mange haemodynamic fluctuation and anticipate and treat ventilator problems in patients undergoing excision of CBT especially when large or bilateral.

A high degree of vigilance should be continued in the postoperative period to detect stroke or identify other cranial nerve deficits. With a team approach to management of CBT, operative complications can be minimized with a good outcome even in patients with large or bilateral tumours.
Funding: Nil, Conflict of interest: None initiated, Permission from IRB: Yes

\section{References}

1. Sen I, Stephen E, Malepathi K, Agarwal S, Shyamkumar NK, Mammen S. Neurological complications in carotid body tumours: a 6-year singlecentre experience. J Vasc Surg. 2013 Feb; 57(2 Suppl): 64S-8S PMID: 23336858 doi:10.1016/j. jvs. 2012.06.114.

2. Luna-Ortiz K, Rascon-Ortiz M, VillavicencioValencia V, Granados-Garcia M, Herrera-Gomez A. 
Carotid body tumours: review of a 20-year experience. Oral Oncol. 2005 Jan; 41(1):56-61. PMID: 15598586 doi:10.1016/j.oraloncology.2004.06.006.

3. Sajid MS, Hamilton G, Baker DM. Joint Vascular Research Group: A multicenter review of carotid body tumour management. Eur J Vasc Endovasc Surg. 2007 Aug; 34(2):127-30. Epub 2007 Apr 2. PMID: 17400487 doi: 10.1016/j.ejvs.2007.01.015.

4. Hallett JW Jr, Nora JD, Hollier LH, Cherry KJ Jr, Pairolero PC. Trends in neurovascular complications of surgical management for carotid body and cervical paragangliomas: a fifty-year experience with 153 tumors. J Vasc Surg. 1988 Feb 7;284-91. PMID: 2828696.

5. Moore JP, Claydon VE, Norcliff LJ, Rivera-Ch MC, Leon-Velarde F, Appenzeller $\mathrm{O}$, et. al. Carotid baroreflex regulation of vascular resistance in highaltitude Andean natives with and without chronic mountain sickness. Exp Physiol. 2006 Sep; 91(5):907913. Epub 2006 Jun 8. PMID: 16763007 doi: 10.1113/expphysiol.2005.033084.

6. Pacheco-Ojeda L, Durango E, Rodriquez C, Vivar N. Carotid body tumors at high altitude: Quito, Ecuador, 1987. World J. Surg. 1988 Dec; 12(6):856- 860. PMID: 3250136 .

7. Lim JY, Kim J, Kim SH, Lee S, Lim YC, Kim JW et al. Surgical treatment of carotid body paragangliomas: outcomes and complications according to the shamblin classification.Clin Exp Otorhinolaryngol. 2010 Jun; 3(2):91-5. Epub 2010 Jun 30. PMID: 20607078 PMCID: PMC2896739 doi: 10.3342/ceo.2010.3.2.91.

8. Hinojosa CA, Ortiz-Lopez LJ, Anaya-Ayala JE, Orozco-Sevilla V, Nunez-Salgado AE. Comparison of retrocarotid and caudocranial dissection techniques for the surgical treatment of carotid body tumors .J Vasc Surg. 2015 Oct;62(4):958-64. Epub 2015 Aug 4 PMID: 26254456 doi: 10.1016/j.jvs.2015.05.001.

9. Amsalu A; Anderson B; Tesfaye W. Giant malignant carotid body tumor in a 40 years old woman: a case report from Gondar University Hospital. Ethiop Med J. 2013 Oct;51(4): 285-91. PMID:24696980.

10. Puggioni A, Delis KT, Fields CE, Viozzi CF, Kallmes DF, Gloviczki P. Large symptomatic carotid body tumor resection aided by preoperative embolization and mandibular subluxation.Perspect Vasc Surg Endovasc Ther. 2005Mar;17(1):21-8. PMID: 15952693

11. Dossa C, Shepard AD, Wolford DG, Reddy DJ, Ernst CB.Distal internal carotid exposure: a simplified technique for temporary mandibular subluxation. J Vasc Surg. 1990 Sep;12(3):319-25. PMID: 2398590.

12. Fisher DF Jr, Clagett GP, Parker JI, Fry RE, Poor MR, Finn RA, Brink BE, Fry WJ. Mandibular subluxation for high carotid exposure. J Vasc Surg. 1984 Nov;1(6):727-33. PMID: 6492304.

13. Bercin S, Muderris T, Sevil E, Gul F, Kilicarslan A, Kiris M. Efficiency of preoperative embolization of carotid body tumor. Auris Nasus Larynx. 2015 Jun;42(3):226-30. Epub 2014 Dec 1. PMID: 25476121 doi: 10.1016/j.anl.2014.10.013.

14. Piazza P, Di Lella F, Bacciu A, Di Trapani G, Ait Mimoune H, Sanna M. Preoperative protective stenting of the internal carotid artery in the management of complex head and neck paragangliomas: long-term results. Audiol Neurootol. 2013;18(6):345-52. Epub 2013 Oct 4. PMID: 24107406 doi: 10.1159/000354158.

15. Gwon JG, Kwon TW, Kim H, Cho YP. Risk factors for stroke during surgery for carotid body tumors. World J Surg. 2011 Sep;35(9):2154-8. PMID: 21717241 doi: 10.1007/s00268-011-1167-7.

16. Pasternak JJ, Lanier WL. J Neuroanesthesiology update. Neurosurg Anesthesiol. 2014 Apr; 26(2):10954. PMID: 24594653 doi: 10.1097/ANA. 0000000000000048.

17. Schifilliti D, Grasso G, Conti A, Fodale V. Anaesthetic-related neuroprotection: intravenous or inhalational agents? CNS Drugs. 2010 Nov; 24(11):893-907. PMID: 20932063 doi: 10.2165 / 11584760-000000000-00000.

18. Murkin JM, Arango M. Near-infrared spectroscopy as an index of brain and tissue oxygenation. Br. J. Anaesth. 2009 Dec;103 Suppl 1:i3-13. 103 (suppl 1): i3-i13. PMID: 20007987 doi:10.1093/bja/aep 299.

19. Stabile E, Sannino A, Schiattarella GG, Gargiulo G, Toscano E, Brevetti L, et al. Cerebral embolic lesions 
detected with diffusion-weighted magnetic resonance imaging following carotid artery stenting: a metaanalysis of 8 studies comparing filter cerebral protection and proximal balloon occlusion. JACC Cardiovasc Interv. 2014 Oct;7(10):1177-83. Epub 2014 Sep 17. PMID: 25240544 doi: 10.1016/j.jcin.2014.05.019.

20. Bauer AM, Smith RB, Thorell WE. Implications of carotid sinus hypersensitivity following preoperative embolization of a carotid body tumour. An indication for prophylactic intraoperative cardiac pacing. Bauer AM, JAMA Otolaryngol Head Neck Surg. 2014 May;140(5):459-63. PMID: 24651937 doi: 10.1001/ jamaoto.2014.144.

21. Gur I, Katz S. Baroreceptor failure syndrome after bilateral carotid body tumorsurgery. Ann Vasc Surg. 2010 Nov;24(8):1138.e1-3. PMID: 21035715 doi: 10.1016/j.avsg.2010.05.022.

22. Onan B, Oz K, Onan IS. Baroreflex failure syndrome: a rare complication of bilateral carotid body tumour excision. Turk Kardiyol Dern Ars. 2010 Jun;38(4):267-70. PMID: 20935434.

23. Marcus NJ, Del Rio R, Schultz HD. Central role of carotid body chemoreceptors in disordered breathing and cardiorenal dysfunction in chronic heart failure.
Front Physiol. 2014 Nov 24;5:438. PMID: 25505417 PMCID: PMC4241833 doi:10.3389/fphys.2014.00438. e Collection 2014.

24. Holmes AP, Turner PJ, Buckler KJ, Kumar P. Moderate inhibition of mitochondrial function augments carotid body hypoxic sensitivity. Pflugers Arch. 2016 Jan;468(1):143-55. PMID: 26490460 doi:10.1007/ s00424-015-1745-x.

25. López-Barneo J, Ortega-Sáenz P, Pardal R, Pascual A, Piruat JI, Durán R, et al. Oxygen sensing in the carotid body. Ann N Y Acad Sci. 2009 Oct;1177:11931. PMID: 19845614 doi:10.1111/j.1749-6632.2009. 05033.x.

26. Niemeijer ND, Corssmit EP, Reijntjes RH, Lammers GJ, van Dijk JG, Thijs RD. Sleep-mediated heart rate variability after bilateral carotid body tumour resection. Sleep. 2015 Apr 1;38(4):633-9. PMID: 25325476 PMCID: PMC4355903 DOI: 10.5665/sleep. 4586 .

27. O'Neill S, O'Donnell M, Harkin D, Loughrey M, Lee B, Blair P. A 22-year Northern Irish experience of carotid body tumours. Ulster Med J. 2011 Sep; 80(3):133-40. PMID: $23526121 \quad$ PMCID: PMC3605524.

\section{How to cite this article?}

Salins S.R, Prabhu P.K, Stephen E, Selvaraj D. Anaesthetic management in the excision of large carotid body tumours: Surgeons perspectives. Int J Med Res Rev 2016;4(8):1493-1501.doi:10.17511/ijmrr.2016.i08.33. 